\title{
KLASTERISASI DATA JAMAAH UMROH PADA AULIYA TOUR \& TRAVEL MENGGUNAKAN METODE $K$-MEANS CLUSTERING
}

\author{
Muhammad Iqbal \\ Sistem Informasi, STMIK Royal Kisaran \\ email: muhammad.iqbal@gmail.com
}

\begin{abstract}
Religious tourism especeeially for Hajj and Umroh is increasingly in demand by the public. Auliya Tour \& Travel, which is engaged in the travel agency, has diverse pilgrimage data so that the data collection is used to find new knowledge as a marketing strategy using Data Mining techniques. Data Mining is one of the KDD processes that has the function for grouping. $K$-Means Clustering is a data mining technique that aims to group data into a data subset. The grouping of data on Umroh pilgrims is conducted to find out the interest groups of pilgrims based on age. This study categorizes pilgrim data into three clusters, which are very popular, in high demand and less desirable. Attributes used in processing data include gender, age, and congregation package. Before the data calculation process is carried out, the data transformation process is carried out before data calculation process. Based on data calculations that have been done through the RapidMiner software, the members of the group were very interested, ranging in age from 56 to 83 years, interested groups ranging in age from 29 to 55 years and the group was less interested with an age range 2 to 22 years from 170 records.
\end{abstract}

Keywords: Clustering, Data Mining, K-Means, RapidMiner, Umroh.

\begin{abstract}
Abstrak: Perjalanan wisata religi khususnya untuk ibadah haji dan umroh semakin diminati masyarakat. Auliya Tour \& Travel yang bergerak pada bidang biro perjalanan memiliki data jamaah yang beragam sehingga kumpulan data tersebut dimanfaatkan untuk menemukan pengetahuan yang baru sebagai strategi pemasaran dengan menggunakan teknik Data Mining. Data Mining merupakan salah satu proses dari KDD yang fungsi salah satunya untuk pengelompokan. K-Means Clustering merupakan salah satu teknik Data Mining yang bertujuan untuk mengelompokkan data ke dalam subset data. Pengelompokan data jamaah umroh dilakukan bertujuan untuk mengetahui kelompok minat jamaah berdasarkan usia. Penelitian ini mengelompokkan data jamaah menjadi tiga cluster yaitu sangat diminati, diminati dan kurang diminati. Atribut yang digunakan dalam pengolahan data meliputi jenis kelamin, usia, dan paket jamaah. Sebelum proses perhitungan data dilakukan terlebih dahulu dilakukan proses transformasi data. Berdasarkan perhitungan data yang telah dilakukan melalui software RapidMiner diperoleh anggota kelompok sangat diminati dari rentang usia mulai 56 sampai 83 tahun, kelompok diminati dengan rentang usia mulai 29 sampai 55 tahun dan kelompok kurang diminati mulai usia 2 sampai 22 tahun dari 170 record.
\end{abstract}

Kata Kunci: Clustering, Data Mining, K-Means, RapidMiner, Umroh. 
JURTEKSI (Jurnal Teknologi dan Sistem Informasi)

Vol. V No. 2, Juni 2019, hlm. 97 - 104

DOI: https://doi.org/10.33330/jurteksi.v5i2.352

Available online at http://jurnal.stmikroyal.ac.id/index.php/jurteksi
ISSN 2407-1811 (Print)

ISSN 2550-0201 (Online)

\section{PENDAHULUAN}

Perkembangan teknologi saat ini semakin pesat dan tidak terbendung. Semakin mudahnya mendapatkan informasi dan proses transaksi data yang cepat menjadi volume data semakin besar. Pertumbuhan data yang sangat cepat dalam waktu yang relatif singkat menjadikan penumpukan data di dalam database. Perkembangan pengetahuan dan teknologi memanfaatkan data yang besar tersebut menjadi suatu pengetahuan baru yang dikenal dengan teknik Data Mining.

Meningkatnya jumlah data jamaah umroh pada Auliya Tour \& Travel tentunya memiliki variasi usia yang berbeda-beda. Pengelompokan usia jamaah merupakan salah satu tujuan untuk meningkatkan kualitas pelayanan. Pengelompokan usia ini bertujuan untuk mengetahui minat keberangkatan umroh pada Auliya Tour \& Travel berdasarkan usia sehingga dibentuk tiga cluster, yaitu Sangat Diminati, Diminati dan Kurang Diminati berdasarkan usia jamaah. Permasalahan yang muncul adalah pihak perusahaan kesulitan dalam mengelompokkan usia jamaah umroh. Berdasarkan latar belakang ini penulis tertarik untuk melakukan penelitian menggunakan $K$ Means Clustering sebagai metode pengelompokan dengan menghitung jarak menggunakan rumus Euclidean di mana data dikelompokkan berdasarkan karakteristik yang sama akan dimasukkan pada kelompok yang sama sehingga data usia jamaah terkelompok dan dimasukkan ke dalam kelompok tidak tumpang tindih.

\section{METODE}

Metodologi penelitian merupakan sistematika keseluruhan tahapan yang akan dilaksanakan selama penelitian. Metodologi berperan penting untuk menjadikan baik atau tidaknya suatu penulisan karya ilmiah. Untuk memperoleh hasil penelitian yang diharapkan maka diperlukan melakukan studi pustaka sebagai referensi dalam penelitian.

Adapun kerangka kerja penelitian ini dapat digambarkan pada Gambar 1.

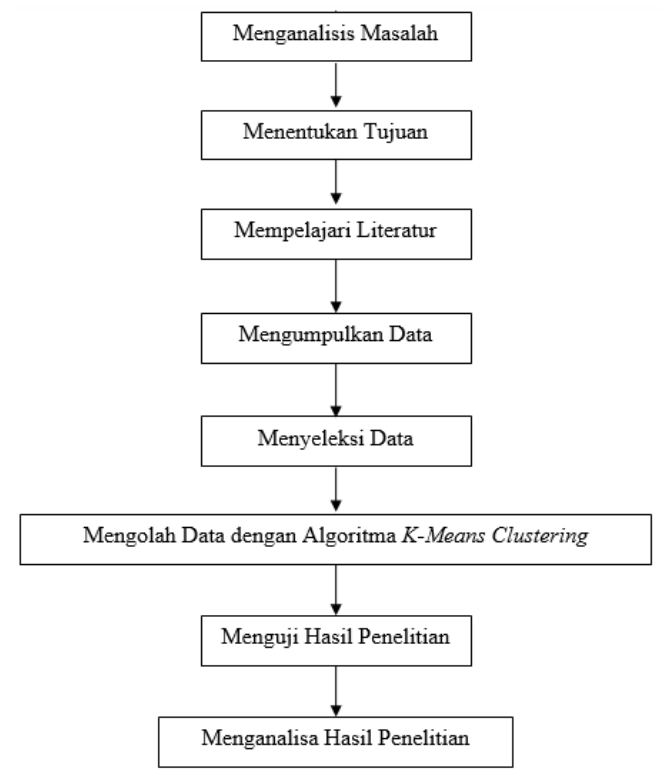

Gambar 1. Kerangka Kerja Penelitian

\section{Knowledge Discovery in Database}

KDD merupakan proses mengekstrak pola atau model dari data dengan menggunakan suatu algoritma yang spesifik. Adapun proses KDD sebagai berikut [1].

\section{Data Selection}

Data operasional perlu dilakukan sebelum tahap penggalian informasi 
JURTEKSI (Jurnal Teknologi dan Sistem Informasi)

Vol. V No. 2, Juni 2019, hlm. 97 - 104

DOI: https://doi.org/10.33330/jurteksi.v5i2.352

Available online at http://jurnal.stmikroyal.ac.id/index.php/jurteksi
ISSN 2407-1811 (Print)

ISSN 2550-0201 (Online) dalam KDD dimulai. Data hasil seleksi yang akan digunakan untuk proses Data Mining disimpan dalam suatu berkas, terpisah dari basis data operasional [1]

2. Pre-processing

Sebelum Data Mining dapat dilaksanakan, perlu dilakukan proses cleaning duplikasi data, memeriksa data yang inkonsisten, dan memperbaiki kesalahan pada data, seperti kesalahan cetak (tipografi). Juga dilakukan enrichment data yang sudah ada dengan data atau informasi lain yang relevan dan diperlukan untuk KDD, seperti data atau informasi eksternal.

3. Transformation

Merupakan proses kreatif dan sangat tergantung pada jenis atau pola informasi yang akan dicari dalam database.

\section{Data Mining}

Sebagai rangkaian kegiatan untuk menemukan pola yang menarik dari data dalam jumlah besar, kemudian data-data tersebut dapat disimpan dalam database, data warehouse atau penyimpanan informasi.

\section{Interpretation / Evalution}

Data Mining ditampilkan dalam bentuk yang mudah dimengerti oleh pihak yang berkepentingan. Tahap ini merupakan bagian dari proses KDD interpretation mencakup pemeriksaan apakah pola atau informasi yang ditemukan bertentangan dengan fakta atau hipotesa yang ada sebelumnya atau tidak.

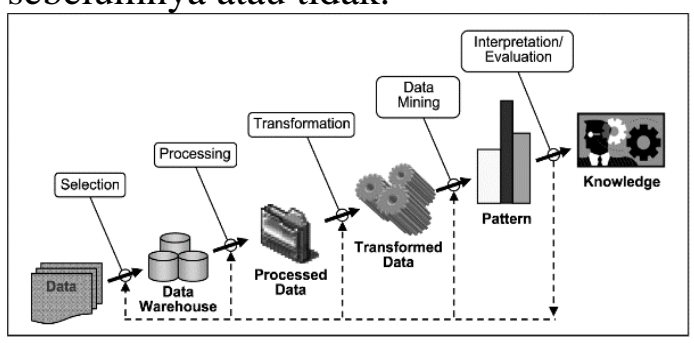

Gambar 2. Proses Knowledge Discovery in Database

\section{Data Mining}

Data Mining merupakan inti dari proses Knowledge Discovery in Database (KDD) yang melibatkan algoritma untuk mengeksplorasi data, mengembangkan model dan menemukan pola yang sebelumnya tidak diketahui juga dikenal sebagai pattern recognition yang digunakan untuk menemukan pola yang tersembunyi dari data yang diolah Metode Data Mining telah dikenal sejak tahun 1990 [3] sebagai salah satu alat untuk pengekstraksian suatu basis data yang berukuran besar guna memperoleh suatu pengetahuan baru.

\section{Clustering}

Clustering merupakan proses membagi data dalam suatu himpunan ke dalam beberapa kelompok yang kesamaan datanya dalam suatu kelompok lebih besar daripada kesamaan data tersebut dengan data dalam kelompok lain Pada dasarnya clustering merupakan metode untuk mencari dan mengelompokkan data yang memiliki kemiripan karakteristik (similiarity) antara satu data dengan data yang lain [5]. Data-data yang memiliki kemiripan karakteristik akan berkumpul dalam kelompok atau cluster yang sama. Data-data yang memiliki perbedaan karakteristik, akan berkumpul dalam kelompok atau cluster yang berbeda. Tujuan utama dari metode clustering adalah pengelompokan sejumlah data atau obyek ke dalam cluster (group) sehingga dalam setiap cluster akan berisi data yang semirip mungkin[6].

\section{Algoritma K-Means}

Algoritma K-Means merupakan algoritma pengelompokan iteratif yang melakukan partisi set data ke dalam sejumlah k cluster yang sudah ditetapkan 
JURTEKSI (Jurnal Teknologi dan Sistem Informasi)

Vol. V No. 2, Juni 2019, hlm. 97 - 104

DOI: https://doi.org/10.33330/jurteksi.v5i2.352

Available online at http://jurnal.stmikroyal.ac.id/index.php/jurteksi
ISSN 2407-1811 (Print)

ISSN 2550-0201 (Online) di awal [3] Algoritma K-Means memiliki ketelitian yang cukup tinggi terhadap ukuran objek, sehingga algoritma ini relatif lebih terukur dan efisien untuk pengolahan objek dalam jumlah besar. Selain itu, algoritma K-Means ini tidak terpengaruh terhadap urutan objek. Salah satu tahapan penting dalam menerapkan K-Means Cluster adalah menentukan centroid, banyaknya cluster dan jarak centroid [4] pada penelitiannya memaparkan tahapan melakukan clustering atau pengelompokan dengan metode K-Means sebagai berikut:

1. Menentukan berapa banyak cluster yang ingin dibentuk, di mana nilai $\mathrm{K}$ adalah banyaknya cluster / jumlah cluster.

2. Menentukan pusat cluster (centroid) awal. Centroid awal ditentukan secara acak dari data yang ada dan jumlah cenroid awal sama dengan jumlah cluster.

3. Setelah menentukan centroid awal, maka setiap data akan menemukan centroid terdekatnya yaitu dengan menghitung jarak setiap data ke masing-masing centroid menggunakan rumus korelasi antar dua obyek yaitu Euclidean Distance.

$$
d_{\text {euclidean }}(x, y)=\sqrt{\sum_{i=1}^{n}\left(x_{i}-y_{i}\right)^{2}}
$$

Di mana:

$\mathrm{d}(\mathrm{x}, \mathrm{y})=$ Jarak data ke $\mathrm{x}$ ke pusat cluster $\mathrm{y} x \mathrm{x}=$ Data ke-i pada atribut data ke $\mathrm{n}$ yi $\quad=$ Data ke-j pada atribut data ke $n$

4. Setelah menghitung jarak data ke centroid-nya, maka langkah berikutnya adalah mengelompokkan data berdasarkan jarak minimumnya.
Suatu data akan menjadi anggota dari suatu cluster yang memiliki jarak terdekat (terkecil) dari pusat clusternya.

5. Berdasarkan pengelompokan tersebut, selanjutnya adalah mencari centroid baru berdasarkan membership dari masing-masing cluster yaitu dengan menghitung rata-rata dari data masingmasing cluster.

6. Kembali ke tahap 3.

7. Perulangan berhenti apabila tidak ada data lagi yang berpindah.

\section{HASIL DAN PEMBAHASAN}

Dimulai dengan mengumpulkan data di mana data tersebut diperoleh dari Auliya Tour \& Travel Kisaran. Kemudian data tersebut diseleksi berdasarkan keperluan penelitian. Data hasil seleksi dilakukan proses transformasi data agar dapat diolah pada metode K-Means.

Data yang telah ditransformasi tersebut siap untuk diolah dengan metode K-Means yang dimulai dari menentukan jumlah cluster.

Pada penelitian ini menggunakan tiga cluster, yaitu Sangat Diminati, Diminati dan Kurang Diminati. Kemudian menentukan nilai titik pusat cluster atau disebut dengan centroid yang diambil secara acak dari dataset.

Setelah titik cluster ditentukan hitung jarak terdekat cluster lalu dikelompokkan berdasarkan jarak terdekat dengan cluster. Hitung kembali nilai centroid baru dengan cara menjumlahkan anggota kelompok dibagi total anggota. 
Available online at http://jurnal.stmikroyal.ac.id/index.php/jurteksi

Tabel 1. Data Sampel Hasil Transformasi

\begin{tabular}{clccc}
\hline NO & & NKAMA & USIA & PAKET \\
\hline 1 & ABDUL HALIM MUHAMMAD NUH & 1 & 8 & 1 \\
\hline 2 & ARMIYANTI ANSARI ITAM & 0 & 6 & 1 \\
\hline 3 & ENNY HALAWATI & 0 & 6 & 1 \\
\hline 4 & ERFINA LEGIMIN YOSO & 0 & 6 & 1 \\
\hline 5 & HENNY SYARIF MUHAMMAD & 0 & 7 & 2 \\
\hline 6 & LOKOT UDIN PANJAITAN & 1 & 8 & 1 \\
\hline 7 & MAIMUNAH ABDUL MUNIR SAINAL & 0 & 8 & 3 \\
\hline 8 & MARTINI DARMAJI SENGUT & 0 & 8 & 1 \\
\hline 9 & MASNUN MUSA HASIBUAN & 0 & 7 & 2 \\
\hline 10 & MISRAN RASUL HASAN & 1 & 6 & 2 \\
\hline 11 & MUHAMMAD JUNAIDI SADINO & 1 & 8 & 1 \\
\hline 12 & NANING WINARSIH SUTARNO & 0 & 5 & 3 \\
\hline 13 & NEZA APRIDILLA & 0 & 2 & 2 \\
\hline 14 & PONI WIRYO SUMARTO & 0 & 8 & 3 \\
\hline 15 & RITAWATI NASIB GURUSINGA & 0 & 7 & 2 \\
\hline 16 & ROSDIANA MUCHTARAM NASUTION & 0 & 8 & 2 \\
\hline 17 & ROSLAINI ISMAIL FIRMAN & 0 & 8 & 1 \\
\hline 18 & SUHARTINI LASIMIN KROMO & 0 & 8 & 1 \\
\hline 19 & SUMARNI SUMARTO ABDULLAH & 0 & 8 & 2 \\
\hline 20 & SUNARMI OSERI ABDULLAH & 0 & 7 & 3 \\
\hline 21 & SUSILAWATI HUSIN TUMAN & 0 & 6 & 2 \\
\hline 22 & TAING MUHAMMAD SARI SITOMPUL & 0 & 7 & 1 \\
\hline 23 & TODUH KETEK ABDULLAH & 0 & 7 & 2 \\
\hline 24 & ZAHIR NAUFAL AR RAZAQ & 1 & 2 & 1 \\
\hline 25 & ZULIJAWATI NGATIMAN MIKAR & 0 & 6 & 2 \\
\hline 26 & ZULISMAR SRI HARTATI & 0 & 6 & 1 \\
\hline & & & & \\
\hline
\end{tabular}

\begin{tabular}{clccc}
\hline \multicolumn{5}{c}{ Tabel 2. Centroid Awal } \\
\hline NO. & \multicolumn{1}{c}{ NAMA } & JK & USIA & PAKET \\
\hline 13 & $\begin{array}{l}\text { NEZA } \\
\text { APRIDILLA }\end{array}$ & 0 & 2 & 2 \\
\hline 16 & $\begin{array}{l}\text { ROSDIANA } \\
\text { MUCHTARA } \\
\text { M NASUTION }\end{array}$ & 0 & 8 & 2 \\
\hline 25 & $\begin{array}{l}\text { ZULIJAWATI } \\
\text { NGATIMAN } \\
\text { MIKAR }\end{array}$ & & 6 & 2 \\
& & & & \\
\end{tabular}

Data sampel baris ke-1 atas nama Abdul Halim Muhammad Nuh dihitung dengan titik centroid ke-1 sebagai DC1, centroid ke-2 sebagai DC2 dan centroid ke-3 sebagai DC3,

di mana:

$\mathrm{DC} 1=\sqrt{(1-0)^{2}+(8-2)^{2}+(1-2)^{2}}=$ 6.164414003
$\mathrm{DC} 2=\sqrt{(1-0)^{2}+(8-8)^{2}+(1-2)^{2}}=$ 1.414213562

DC3 $=\sqrt{(1-0)^{2}+(8-6)^{2}+(1-2)^{2}}=$ 2.449489743

Jadi, nilai terkecil baris ke-1 terdapat pada DC2 maka data jamaah baris ke-1 ditempatkan pada kelompok C2.

Perhitungan dilanjutkan sampai baris data ke-26 dan mendapatkan hasil penempatan anggota cluster berdasarkan kelompok

Lakukan iterasi untuk menghitung jarak minimum dengan nilai centroid baru dan mengelompokkan anggota cluster, apabila anggota cluster sudah tidak mengalami perubahan tempat maka iterasi dihentikan dan anggota kelompok telah ditemukan. 
JURTEKSI (Jurnal Teknologi dan Sistem Informasi)

Vol. V No. 2, Juni 2019, hlm. 97 - 104

DOI: https://doi.org/10.33330/jurteksi.v5i2.352

Available online at http://jurnal.stmikroyal.ac.id/index.php/jurteksi
ISSN 2407-1811 (Print)

ISSN 2550-0201 (Online)

Tabel 3. Hasil Perhitungan Jarak dan Pengelompokan Pada Iterasi Ke-1

\begin{tabular}{|c|c|c|c|c|c|c|c|}
\hline NO & NAMA & DC1 & DC2 & DC3 & C1 & C2 & C3 \\
\hline 1 & $\begin{array}{l}\text { ABDUL HALIM } \\
\text { MUHAMMAD NUH }\end{array}$ & 6.164414003 & 1.414213562 & 2.449489743 & & 1 & \\
\hline 2 & $\begin{array}{l}\text { ARMIYANTI ANSARI } \\
\text { ITAM }\end{array}$ & 4.123105626 & 2.236067977 & 1 & & & 1 \\
\hline 3 & ENNY HALAWATI & 4.123105626 & 2.236067977 & 1 & & & 1 \\
\hline 4 & ERFINA LEGIMIN YOSO & 4.123105626 & 2.236067977 & 1 & & & 1 \\
\hline 5 & $\begin{array}{l}\text { HENNY SYARIF } \\
\text { MUHAMMAD }\end{array}$ & 5 & 1 & 1 & & 1 & \\
\hline 6 & $\begin{array}{l}\text { LOKOT UDIN } \\
\text { PANJAITAN }\end{array}$ & 6.164414003 & 1.414213562 & 2.449489743 & & 1 & \\
\hline 7 & $\begin{array}{l}\text { MAIMUNAH ABDUL } \\
\text { MUNIR SAINAL }\end{array}$ & 6.08276253 & 1 & 2.236067977 & & 1 & \\
\hline 8 & $\begin{array}{l}\text { MARTINI DARMAJI } \\
\text { SENGUT }\end{array}$ & 6.08276253 & 1 & 2.236067977 & & 1 & \\
\hline 9 & $\begin{array}{l}\text { MASNUN MUSA } \\
\text { HASIBUAN }\end{array}$ & 5 & 1 & 1 & & 1 & \\
\hline 10 & MISRAN RASUL HASAN & 4.123105626 & 2.236067977 & 1 & & & 1 \\
\hline 11 & $\begin{array}{l}\text { MUHAMMAD JUNAIDI } \\
\text { SADINO }\end{array}$ & 6.164414003 & 1.414213562 & 2.449489743 & & 1 & \\
\hline 12 & $\begin{array}{l}\text { NANING WINARSIH } \\
\text { SUTARNO }\end{array}$ & 3.16227766 & 3.16227766 & 1.414213562 & & & 1 \\
\hline 13 & NEZA APRIDILLA & 0 & 6 & 4 & 1 & & \\
\hline 14 & PONI WIRYO SUMARTO & 6.08276253 & 1 & 2.236067977 & & 1 & \\
\hline 15 & $\begin{array}{l}\text { RITAWATI NASIB } \\
\text { GURUSINGA }\end{array}$ & 5 & 1 & 1 & & 1 & \\
\hline 16 & $\begin{array}{l}\text { ROSDIANA } \\
\text { MUCHTARAM } \\
\text { NASUTION }\end{array}$ & 6 & 0 & 2 & & 1 & \\
\hline 17 & $\begin{array}{l}\text { ROSLAINI ISMAIL } \\
\text { FIRMAN }\end{array}$ & 6.08276253 & 1 & 2.236067977 & & 1 & \\
\hline 18 & $\begin{array}{l}\text { SUHARTINI LASIMIN } \\
\text { KROMO }\end{array}$ & 6.08276253 & 1 & 2.236067977 & & 1 & \\
\hline 19 & $\begin{array}{l}\text { SUMARNI SUMARTO } \\
\text { ABDULLAH }\end{array}$ & 6 & 0 & 2 & & 1 & \\
\hline 20 & $\begin{array}{l}\text { SUNARMI OSERI } \\
\text { ABDULLAH }\end{array}$ & 5.099019514 & 1.414213562 & 1.414213562 & & 1 & \\
\hline 21 & $\begin{array}{l}\text { SUSILAWATI HUSIN } \\
\text { TUMAN }\end{array}$ & 4 & 2 & 0 & & & 1 \\
\hline 22 & $\begin{array}{l}\text { TAING MUHAMMAD } \\
\text { SARI SITOMPUL }\end{array}$ & 5.099019514 & 1.414213562 & 1.414213562 & & 1 & \\
\hline 23 & $\begin{array}{l}\text { TODUH KETEK } \\
\text { ABDULLAH }\end{array}$ & 5 & 1 & 1 & & 1 & \\
\hline 24 & $\begin{array}{l}\text { ZAHIR NAUFAL AR } \\
\text { RAZAQ }\end{array}$ & 1.414213562 & 6.164414003 & 4.242640687 & 1 & & \\
\hline 25 & $\begin{array}{l}\text { ZULIJAWATI NGATIMAN } \\
\text { MIKAR }\end{array}$ & 4 & 2 & 0 & & & 1 \\
\hline 26 & ZULISMAR SRI HARTATI & 4.123105626 & 2.236067977 & 1 & & & 1 \\
\hline
\end{tabular}


DOI: https://doi.org/10.33330/jurteksi.v5i2.352

Available online at http://jurnal.stmikroyal.ac.id/index.php/jurteksi

Data yang dihasilkan dalam bentuk clustering atau kelompok data jamaah umroh.

$$
\begin{aligned}
\mathbf{C} 1=\frac{(1+0)}{2}=0.5 \\
\frac{(2+2)}{2}=2 \\
\frac{(1+2)}{2}=1.5 \\
\text { C1 }=\mathbf{0 . 5 , 2}, \mathbf{1 . 5} \\
\mathrm{C} 2=
\end{aligned}
$$

$\frac{(1+0+1+0+0+0+1+0+0+0+0+0+0+0+0+0)}{16}$ $=0.1875$

$\underline{(8+7+8+8+8+7+8+8+7+8+8+8+8+7+7+7)}$ $=7.625$

$\underline{(1+2+1+3+1+2+1+3+2+2+1+1+2+3+1+2)}$

$$
16
$$

Iterasi selanjutnya dilakukan perhitungan kembali dengan menggunakan titik centroid yang baru. Proses perhitungan tetap dengan menggunakan rumus Euclidean Distance.

Setelah didapatkan hasil iterasi pertama dan kedua kemudian dibandingkan dan diperoleh posisi anggota cluster pada iterasi pertama dan kedua tidak mengalami perubahan sehingga proses iterasi dihentikan dan hasil akhir yang diperoleh yaitu:

1. Kelompok Sangat diminati terdiri dari 16 anggota dengan kategori umur 7 sampai 8 yaitu rentang usia dari 49 tahun sampai 65 tahun.

2. Kelompok Diminati terdiri dari 8 anggota dengan kategori umur 5 sampai 6 yaitu rentang usia dari 34 tahun sampai 45 tahun.

3. Kelompok Kurang Diminati terdiri dari 2 anggota dengan kategori

$$
=1.75
$$

$$
\begin{aligned}
\mathbf{C} 2= & \mathbf{0 . 1 8 7 5 , 7 . 6 2 5 , 1 . 7 5} \\
\mathbf{C} 3= & \frac{(0+0+0+1+0+0+0+0)}{8}=0.125 \\
& \frac{(6+6+6+6+5+6+6+6)}{8}=5.875 \\
& \frac{(1+1+1+2+3+2+2+1)}{8}=1.625 \\
\mathbf{C 3}= & \mathbf{0 . 1 2 5 , 5 . 8 7 5 , 1 . 6 2 5}
\end{aligned}
$$

Dari hasil rata-rata di atas didapatkan nilai pusat cluster baru yang ditampilkan dalam bentuk Tabel 4 sebagai berikut:

Tabel 4 Nilai Centroid Baru Untuk Iterasi Ke-2

\begin{tabular}{cccc}
\hline CLUSTER & \multicolumn{4}{c}{ NILAI CENTROID BARU } \\
\hline C1 & 0.5 & 2 & 1.5 \\
\hline C 2 & 0.1875 & 7.625 & 1.75 \\
\hline C 3 & 0.125 & 5.875 & 1.625 \\
\hline
\end{tabular}

umur 2 yaitu rentang usia 8 tahun sampai 11 tahun.

Hasil di atas merupakan hasil dari 26 sampel data yang diuji. Hasil pengelompokan usia jamaah umroh dapat membantu Auliya Tour \& Travel dalam melihat kelompok jamaah berdasarkan usia.

\section{SIMPULAN}

Berdasarkan penelitian yang dilakukan dalam mengelompokan data jamaah umroh pada Auliya Tour \& Travel Kisaran dengan K-Means Clustering, maka dapat diambil kesimpulan sebagai berikut:

1. Variabel yang mempengaruhi dalam pengelompokan data terdiri jenis kelamin, usia dan paket yang 
DOI: https://doi.org/10.33330/jurteksi.v5i2.352

Available online at http://jurnal.stmikroyal.ac.id/index.php/jurteksi

telah mengalami proses transformasi data.

2. Data yang diperoleh dari Auliya Tour \& Travel masih berbentuk teks sehingga diperlukan penyeleksian dan transformasi data ke dalam bentuk numberik agar dapat diproses pada algoritma KMeans.

3. Perancangan sistem metode $\mathrm{K}$ Means dimulai dari mengumpulkan data, seleksi dan transformasi data setelah itu sistem akan menghitung dan menampilkan.

4. Pengujian data sebanyak 170 record diolah dengan Software RapidMiner untuk mendapatkan hasil pengelompokan dalam waktu singkat.

\section{UCAPAN TERIMA KASIH}

Terima kasih kepada Pimpinan dan Staf Auliya Tour \& Travel Kisaran yang telah banyak memberikan dukungan dalam penelitian ini.

\section{DAFTAR PUSTAKA}

[1] Kurniawansyah, A. S. (2018) 'Implementasi Metode Artificial Neural Network dalam Memprediksi Hasil Ujian Kompetensi Kebidanan (Studi Kasus: Akademi Kebidanan Dehasen Bengkulu', Jurnal Pseudocode, 5(1), Februari 2018, pp. 37-44.

[2] Musharyadi, F. (2017) 'Tingkat
Pemahaman Mahasiswa

Terhadap Norma Norma Agama Islam Menggunakan Algoritma K-Means Clustering', Menara Ilmu 11(78), November 2017, pp. 48-54.

[3] Nuryaman, Y., Asistyasari, A. dan Yudha, A. (2018) 'Komparasi Algoritma K-Mean dan AHC untuk klasifikasi curah hujan di Indonesia', IkraithInformatika, 2(2), Juli 2018, pp. 70-75.

[4] Aranda, J. dan Natasya, W. A. G (2016) 'Penerapan Metode KMeans Cluster Analysis Pada Sistem Pendukung Keputusan Pemilihan Konsentrasi Untuk Mahasiswa International Class STMIK AMIKOM Yogyakarta', Seminar Nasional Teknologi Informasi dan Multimedia 2016, (January 2018), pp. 6-7.

[5] Mardalius, Mardalius. "Pemanfaatan Rapid Miner $\begin{array}{lll}\text { Studio } & 8.2 \quad \text { Untuk }\end{array}$ Pengelompokan Data Penjualan Aksesoris Menggunakan Algoritma K-Means. " JURTEKSI 4.2 (2018): 123132.

[6] Sibuea, Mustika Larasati, and Andy Safta. "Pemetaan Siswa Berprestasi Menggunakan Metode K-Means Clustring ." JURTEKSI 4.1 (2017): 85-92 